\title{
Pendidikan Kesehatan terhadap Kader tentang Intervensi Gizi Spesifik dalam Pencegahan Stunting
}

\author{
Firdawsyi Nuzula, Maulida Nurfazriah Oktaviana, Rizky Dwi Yanti Yunita
}

Akademi Kesehatan Rustida, Program Studi DIII Keperawatan, Jl. RSU Bakti

Husada Glenmore, Dusun Krajan, Tegalharjo, Banyuwangi, Kabupaten

Banyuwangi, Jawa Timur

Email: nuzulafirdawsyi@gmail.com

$\begin{array}{ll}\text { Diterima } & : 9 \text { November } 2020 \\ \text { Disetujui } & : 1 \text { Desember } 2020 \\ \text { Dipublikasikan } & : \text { 10 Desember } 2020\end{array}$

\begin{abstract}
Abstrak
Latar Belakang dan Tujuan: Stunting merupakan salah satu dari triple burden masalah gizi dimana diakibatkan oleh kekurangan gizi kronis terutama pada 1000 hari pertama kehidupan (HPK) yang mengakibatkan anak mengalami gagal tumbuh. HPK merupakan gerakan mempercepat perbaikan gizi untuk memperbaiki kehidupan anak dimasa yang akan datang sebagai upaya untuk menurunkan prevalensi stunting. Penelitian ini bertujuan untuk mengetahui pengaruh pemberdayaan kader terhadap intervensi gizi spesifik dalam pencegahan terjadinya stunting di Pukesmas Songgon.

Metode: Metode penelitian ini Quasi eksperimen, dengan menggunakan pendekatan Pretest-Posttest Control Group Design. Uji analisis menggunkan uji Mann Whitney.

Hasil: Ada perbedaan pengetahuan kader yang cukup signifikan setelah mendapatkan pendidikan kesehatan tentang intevensi gizi spesifik dalam pencegahan stunting dengan nilai 0,039 , dan tidak terdapat perbedaan praktik kader terhadap intevensi gizi spesifik dalam pencegahan stunting setelah mendapatkan pendidikan kesehatan dengan nilai 0,422 .

Simpulan dan Implikasi: Pengetahuan kader terhadap intevensi gizi spesifik dalam pencegahan stunting didapatkan perbedaan pengetahuan kader yang cukup signifikan setelah diberikan pendidikan kesehatan. Kader sebagai kepanjangan tangan petugas kesehatan di masyarakat perlu diberikan edukasi oleh petugas kesehatan agar memahami pencegahan stunting.
\end{abstract}

Kata Kunci: Intervensi gizi; Pemberdayaan kader; Stunting

Sitasi: Nuzula F, Oktaviana M N \& Yunita R D Y. (2020). Pendidikan kesehatan terhadap kader tentang intervensi gizi spesifik dalam pencegahan stunting. The Indonesian Journal of Health Science. 12(2), 209215

Copyright: (C) 2020 Nuzula et. al. This is an open-access article distributed under the terms of the Creative Commons Attribution-NonCommercial 4.0 International License, which permits unrestricted use, distribution, and reproduction in any medium, provided the original author and source are credited.

Diterbitkan Oleh: Universitas Muhammadiyah Jember

ISSN (Print): 2087-5053

ISSN (Online): 2476-9614 


\begin{abstract}
Background and Aim: Stunting is one of the triple burdens of nutritional problems which is caused by chronic malnutrition, especially in the first 1000 days of life (HPK) which causes children failed to thrive. HPK is a movement to accelerate the improvement of nutrition to improving the lives of children in the future as an effort to reduce the prevalence of stunting. This study aims to determine the effect of cadre empowerment on specific nutritional interventions in preventing stunting at Pukesmas Songgon.

Methods: This research method is Quasi-experimental, using the Pretest-Posttest Control Group Design approach. The analysis test used the Mann Whitney test. Results: The results of this study indicate that there is a significant difference in the knowledge of cadres after receiving health education about specific nutritional interventions in preventing stunting with a value of 0.039, and there is no difference in cadres' practice of specific nutritional interventions in preventing stunting after receiving health education with a value of 0.422 .

Conclusion: Cadres 'knowledge of specific nutritional interventions in preventing stunting showed a significant difference in cadres' knowledge after being given health education. Cadres as an extension of health workers in the community need to be educated by health workers in order to understand stunting prevention.
\end{abstract}

Keywords: Cadre empowerment; Nutrition intervention; Stunting

\section{PENDAHULUAN}

Stunting merupakan salah satu dari triple burden masalah gizi dimana diakibatkan oleh kekurangan gizi kronis terutama pada 1000 hari pertama kehidupan (HPK) yang mengakibatkan anak mengalami gagal tumbuh (Bappenas, 2015). Setiap anak berhak untuk mendapatkan Air Susu Ibu (ASI). Ikatan emosional antara ibu dan anak dapat lebih baik dengan pemberian ASI dan hal tersebut mampu meningkatkan kualitas manusia di setiap negara (Destyana, 2018).

Memberikan ASI eksklusif dapat mengurangi angka kematian pada Balita serta mencegah terjadinya kelaparan dan malnutrisi, meningkatkan perkembangan mental dan kognitif bayi dan mampu mengoptimalkan pertumbuhan anak (Anisa, 2012). Status gizi bayi akan terjamin selama diberikan ASI serta mampu menurunkan angka kesakitan dan angka kematian anak karena adanya faktor protektif dan nutrien yang sesuai dengan kebutuhan bayi ( Aisyaroh, 2017).

Berdasarkan besaran masalah kekurangan gizi di Indonesia angka stunting selalu menjadi angka tertinggi yaitu $37,2 \%$ dibandingkan dengan berat badan lahir rendah sebanyak $10,2 \%$ dan berat badan yang tidak sesuai dengan usia (gizi kurang) yang mencapai 19,6\% (6). Menurut pemantauan status gizi (PSG) dan Ditjen Kesehatan Masyarakat pada tahun 2015 prevalensi Balita pendek sebanyak $10,1 \%$ dan sangat pendek mencapai $18,9 \%$, pada tahun 2016 menurun untuk Balita pendek menjadi 8,5\% dan Balita sangat pendek sedikit meningkat yaitu $19,0 \%$ sedangkan pada tahun 2017 kembali meningkat untuk Balita pendek menjadi 9,8\% dan Balita sangat pendek mencapai 19,8\% (Kemenkes, 2017). Hampir 9 
juta atau lebih dari $1 / 3$ balita di Indonesia mengalami stunting (PKGBM, 2016). Kabupaten Banyuwangi kejadian stunting dari 7,3\% meningkat menjadi $9,8 \%$ pada bulan timbang Februari dan Agustus 2019 dengan angka tertinggi pada wilayah kerja Puskesmas Songgon yaitu sebanyak 213 kasus (Dinkes, 2015).

Pemerintah telah meluncurkan Rencana Aksi Nasional Penanganan Stunting pada bulan Agustus 2017, yang menekankan pada kegiatan konvergensi di tingkat Nasional, Daerah dan Desa, untuk memprioritaskan kegiatan intervensi Gizi Spesifik dan Gizi Sensitif pada 1.000 Hari Pertama Kehidupan hingga sampai dengan usia 6 tahun (Kemenkes, 2017). Gerakan tersebut bertujuan untuk mempercepat perbaikan gizi untuk memperbaiki kehidupan anak-anak Indoneisa dimasa yang akan datang sebagai upaya untuk menurunkan prevalensi stunting serta bentuk-bentuk kurang gizi lainnya (Kemenkes RI, 2017).

\section{METODE PENELITIAN}

Jenis penelitian adalah Quasi eksperimen design, dengan menggunakan pendekatan PretestPosttest Control Group Design, variabel bebas penelitian yaitu Pemberian pendidikan kepada kader posyandu tentang intervensi spesifik stunting, variabel terikat Pengetahuan dan praktik (Sugiyono, 2017). Analisis univariat menggunakan uji Chi Square. Analisis bivariat menggunakan uji Mann Whitne.

\section{HASIL}

Kriteria responden dalam penelitian ini adalah kader yang telah memiliki pengalaman menjadi kader $>$ dari 5 tahun sehingga diharapkan memiliki pengalaman dalam hal gizi dan pencegahan stunting. Dari tabel 1 dapat dilihat bahwa responden sebagian besar berada pada rentang usia 31 - 35 tahun sebanyak 7 orang (23\%), pendidikan terakhir sebagian besar memiliki pendidikan terakhir SMP sebanyak 17 orang (57\%), seluruh responden telah menjadi kader selama $\geq 5$ Tahun, dan sebagian besar responden memiliki pekerjaans sebagai ibu rumah tangga (IRT) sebanyak 23 orang (77\%). Dari tabel 2 dapat dilihat bahwa pengetahuan kader sebelum nilai cukup 7\%, baik 93\%, setelah diberikan pendiidkan kesehatan mengalami peningkatan bail $100 \%$. Pada praktik kader sebelum diberikan pendidikan kesehatan nilai cukup $77 \%$, setelah diberikan pendidikan kesehatan menjadi cukup $80 \%$.

Output hasil uji mannwhitney $U$ dapat dilihat bahwa nilai mann-whitney U sebesar 320.000 ; Zscore - 2,060; nilai probabilitas/ Asymp. Sig. (2-tailed) (sig) >0,05 $(0,039 \mathrm{p}<0,05)$, dengan demikian dapat disimpulkan bahwa terdapat perbedaan pengetahuan kader yang cukup signifikan setelah mendapatkan pendidikan kesehatan tentang intevensi gizi spesifik dalam pencegahan stunting (Tabel 3).

Sedangkan untuk praktik kader dalam pencegahan stunting diketahui dari output hasil uji mannwhitney U dapat dilihat bahwa nilai mann-whitney U sebesar 397.000 ; Zscore - 0,803; nilai probabilitas/ Asymp. Sig. (2-tailed) (sig) >0,05 $(0,422 \mathrm{p}>0,05)$, dengan demikian dapat disimpulkan bahwa tidak terdapat perbedaan praktik kader sebelum dan sesudah intervensi. 
Tabel 1. Distribusi Responden

\begin{tabular}{|c|c|c|c|}
\hline \multicolumn{2}{|c|}{ Karakteristik } & Jumlah & Prosentase $(\%)$ \\
\hline \multirow[t]{6}{*}{ Umur } & $20-25$ & 3 & 10 \\
\hline & $26-30$ & 6 & 20 \\
\hline & $31-35$ & 7 & 23 \\
\hline & $36-40$ & 6 & 20 \\
\hline & $41-45$ & 6 & 20 \\
\hline & $46-50$ & 2 & 7 \\
\hline \multicolumn{2}{|c|}{ Total Responden } & 30 & 100 \\
\hline Pendidikan & SD & 4 & 13 \\
\hline \multirow[t]{2}{*}{ Terakhir } & SMP & 17 & 57 \\
\hline & SMA & 9 & 30 \\
\hline \multicolumn{2}{|c|}{ Total Responden } & 30 & 100 \\
\hline \multicolumn{4}{|l|}{ kader } \\
\hline \multicolumn{2}{|c|}{ Total Responden } & 30 & 100 \\
\hline \multirow[t]{2}{*}{ Pekerjaan } & IRT & 23 & 77 \\
\hline & Wiraswasta & 7 & 23 \\
\hline \multicolumn{2}{|c|}{ Total Responden } & 30 & 100 \\
\hline
\end{tabular}

Tabel 2 Frekuensi pengetahaun dan praktik kader terhadap Intevensi Gizi Spesifik Dalam Pencegahan Stunting

\begin{tabular}{llcccccc}
\hline \multirow{2}{*}{ Variabel } & & \multicolumn{2}{c}{ Kurang } & \multicolumn{2}{c}{ Cukup } & \multicolumn{2}{c}{ Baik } \\
& & $\mathrm{f}$ & $\%$ & $\mathrm{f}$ & $\%$ & $\mathrm{f}$ & $\%$ \\
\hline $\begin{array}{l}\text { Pengetahuan kader } \\
\text { kesehatan }\end{array}$ & Sebelum & 0 & 0 & 2 & 7 & 28 & 93 \\
& Setelah & 0 & 0 & 0 & 0 & 30 & 100 \\
$\begin{array}{l}\text { Praktik kader } \\
\text { kesehatan }\end{array}$ & Sebelum & 2 & 7 & 23 & 77 & 5 & 17 \\
& Setelah & 1 & 3 & 24 & 80 & 5 & 17 \\
\hline
\end{tabular}

Tabel 3 Hasil Analisis Univariat Mann-Whitney U Tingkat Pengetahuan

\section{Test Statistics}

\begin{tabular}{lr} 
& Pengetahuan \\
Mann-Whitney & 320.000 \\
Wilcoxan W & 785.000 \\
Z & -2.060 \\
Asymp. Sig. (2.tailed) & .039 \\
\hline
\end{tabular}

Tabel 4. Hasil Analisis Univariat Mann-Whitney U Tingkat Praktik

\section{Test Statistics}

\begin{tabular}{lr} 
Mann-Whitney & 397.500 \\
Wilcoxan W & 862.500 \\
Z & -803 \\
\hline Asymp. Sig. (2.tailed) & .422 \\
\hline
\end{tabular}




\section{PEMBAHASAN}

Tingginya angka stunting pada anak di kabupaten Banyuwangi masih menjadi masalah yang serius oleh karena dampak buruk yang ditimbulkan dapat mempengaruhi masa depan anak dan generasi bangsa. Stunting merupakan masalah kurang gizi kronis akibat kurangnya asupan gizi dalam waktu yang cukup lama yang terjadi sejak dari kandungan dan akan mulai nampak saat anak berusia dua tahun. Stunting meningkatkan morbiditas dan mortalitas pada anak (Bappenas, 2018). Penelitian ini untuk mengetahui efektifitas pendidikan kesehatan tentang intervensi gizi spesifik terhadap pencegahan stunting yang diberikan oleh sumber ahli kepada para kader dari posyandu yang berada di wilayah kerja Puskesmas Songgon Kabupaten Banyuwangi. Berdasarkan dari hasil analisis didapatkan nilai $\mathrm{p}<0,05$ untuk variabel pengetahuan dimana diketahui dari hasil uji statistik menunjukkan bahwa kegiatan pelatihan yang diberikan kepada para kader kesehatan memberikan pengaruh terhadap peningkatan pengetahuan para kader kesehatan. Pengetahuan kader posyandu terjadi peningkatan yang signifikan sebelum dan sesudah diberikan oleh ahli gizi dari dinas kesehatan kabupaten Banyuwangi, pengarahan dengan metode ceramah dan tanya jawab melalui virtual, sedangkan untuk simulasi dan praktik tidak bisa dilakukan secara langsung oleh karena situasi masih dalam masa pandemi dimana semua kegiatan posyandu sementara dihentikan dalam waktu yang tidak ditentukan.

Hal ini sejalan dengan penelitian yang dilakukan oleh (Anggraeni et al, 2019) dalam penelitiannya didapatkan hasil nilai $\mathrm{p}$ sebesar $0,000<0,05$ dengan demikian terdapat perbedaan perilaku pada responden atau kader setelah diberikan pendidikan kesehatan. Metode yang sama diaplikasikan oleh Solehati et al di Bandung dalam Diketahui pengetahuan sebelum intervensi kurang dan sebagian besar cukup meningkat menjadi cukup dan sebagian besar baik yaitu dengan nilai presentase 60 menjadi 90 (Solehati et al, 2018).

Memantau pertumbuhan dan perkembangan pada balita merupakan salah satu cara untuk mengatasi terjadinya stunting, dan hal tersebut dapat dilakukan mulai dari tingkat pelayanan kesehatan dasar utamanya posyandu oleh karena itu seorang kader posyandu harus terlatih dan berpengetahuan baik karena merekalah yang akan melakukan deteksi dini pertumbuhan dan perkembangan anak (Aidha. 2017). Apabila diketahui seorang anak mengalami gangguan pertumbuhan maupun perkembangannya maka seorang kader posyandu akan mengajarkan orang tua anak untuk memberikan rangsangan dan apabila tidak didapati suatu perubahan maka tugas kader untuk melaporkan hal tersebut ke puskesmas (Hendrawati, 2018.) Tingginya angka stunting di Kabupaten Banyuwangi seperti yang diangkapkan oleh kepala dinas kesehatan dikhawatirkan karena ada keterkaitan dengan pelaksanaan pengukuran yang kurang tepat, pemberian informasi tentang tumbuh kembang yang kurang jelas ataupun memang dikarenakan adanya pola pengasuhan anak yang salah. Akan tetapi berdasarkan dari hasil analisis data frekuensi dari variabel 
pengetahuan sebelum dan sesudah intervensi tidak mengalami begitu banyak perbedaan, rata-rata pengetahuan kader berpengetahuan baik. Secara teori pengetahuan yang baik merupakan langkah awal bagi seseorang untuk merubah sikap dan perilaku, bagi kader jika memiliki dasar pengetahuan yang baik dan benar maka diharapkan dalam setiap praktik dan kegiatan posyandu maka akan dapat dilaksanakan secara benar dan optimal.

Peningkatan pengetahuan, sikap dan perilaku tersebut dapat dilakukan salah satunya melalui pendidikan kesehatan. Penyuluhan kesehatan dianggap suatu upaya untuk menjembatani adanya kesenjangan antara informasi kesehatan dan juga prakteknya. Apabila informasi kesehatan yang dimiliki telah benar maka kemudian akan menjadikan suatu motivasi untuk menerapkan informasi tersebut (Nugrahaeni, 2018). Strategi penurunan stunting meliputi dua intervensi yaitu intervensi gizi spesifik yang merupakan intervensi live saving jangka pendek dengan memfokuskan pada gizi ibu hamil dan anak pada 1000 HPK serta intervensi gizi sensitif yaitu intervensi dibidang non kesehatan. Pada kenyataannya kedua strategi intervensi tersebut belum mendapatkan hasil sesuai dengan target karena belum sepenuhnya dilaksanakan sesuai dengan rancangannya (Kemenkes RI, 2013).

\section{SIMPULAN}

Hasil penelitian ini
menunjukkan bahwar adanya
perbedaan pengetahuan kader yang
cukup signifikan setelah
mendapatkan pendidikan kesehatan
tentang intevensi gizi spesifik dalam

pencegahan stunting dan tidak terdapat perbedaan praktik kader terhadap intevensi gizi spesifik dalam pencegahan stunting setelah mendapatkan pendidikan kesehatan.

\section{SARAN}

Peneliti selanjutnya diharapkan ada pendampingan pada kader secara berkala untuk memantau proses pelaksanaan kegiatan posyandu untuk mengurangi kemungkinan terjadinya kesalahan.

\section{DAFTAR PUSTAKA}

Bappenas. (2018). Pedoman pelaksanaan intervensi penurunan stunting terintegrasi di kabupaten/ kota (edisi Nove).

Dinkes Kab. Banyuwangi. (2013). Profil kesehatan kabupaten banyuwangi tahun 2013. (Pemerintah Kabupaten Banyuwangi Dinas Kesehatan).

Hendrawati, S., Mardhiyah, A., Mediani, H. S., Nurhidayah, I., \& Mardiah, W. (2018). Pemberdayaan Kader posyandu dalam stimulasi deteksi dan intervensi dini tumbuh kembang (SDIDTK) pada anak usia $0-6$ tahun. MKK, 1(1), 39-58.

Kemenkes RI. (2013). Riset kesehatan dasar 2013. 1-306.

Kemenkes RI. (2015). Infodatin ASI. Pusat Data dan Informasi Kementerian Kesehatan RI.

Kemenkes RI. (2017). Pedoman penyelenggaraan program ASI (PAS) sedunia.

Kemenkes RI. (2018). Hasil pemantauan status gizi (PSG) tahun 2017. Gerakan Masyarakat Hidup Sehat.

Kemenkom. (2011). Program penanggulangan kemiskinan 
kabinet indonesia bersatu II. In Kementerian Komunikasi dan Informasi Direktorat Jendral Informasi Dan Komunikasi Publik (editi terb).

Noveri Aisyaroh, Is Susiloningtyas, M. (2016). Pengembangan intervensi MP-ASI dengan metode demonstrasi pada kader posyandu di desa batur kecamatan getasan kabupaten semarang. Prosiding Seminar Nasional Dan Internasional Universitas Muhammadiyah Semarang, 573-577.

Nugrahaeni, D. E. (2018). Pencegahan balita gizi kurang melalui penyuluhan media lembar balik gizi. 113-124. https://doi.org/10.20473/amnt.v 2.i1.2018.113-124

Paramitha Anisa. (2012). Faktor faktor yang berhubungan dengan kejadian stunting pada balita usia 25 - 60 bulan di Kelurahan Kalibaru Depok tahun 2012. Universitas Indonesia.

Solehati, T., Windani, C., Sari, M., Lukman, M., \& Kosasih, C. E.
(2018). Pengaruh pendidikan kesehatan terhadap pengetahuan dalam upaya menurunkan aki pada kader posyandu. Jurnal Keperawatan Komprehensif, 4(1), 7-12.

Sugiyono. (2017). Metode penelitian bisnis (pendekatan kuantitatif, kualitatif, kombinasi dan R\&D). In Metodelogi Penelitian.

Tyas Ning Yuni Astuti Anggraeni, Ekawati. (2019). Perilaku kader dalam pemantauan tumbuh kembang balita the effect of health education on knowledge and behavior of cadres in monitoring the growth development of toodlers. Media Ilmu Kesehatan, 8(3).

Zuhrina Aidha. 2017. Analisis Implementasi pemberdayaan masyarakat dalam strategi promosi kesehatan dan pengaruhnya terhadap partisipasi masyarakat dalam pencegahan gizi buruk pada balita di Kecamatan Helvetia Medan. (2017). Jurnal Jumantik, 2(2), 31-41. 